nephron

Experimental

Nephrology

and Genetics
Nephron 2019;141:133-146

DOI: $10.1159 / 000495270$
Received: September 27, 2018

Accepted after revision: November 1, 2018

Published online: December 14, 2018

\title{
Molecular Basis of Cystinosis: Geographic Distribution, Functional Consequences of Mutations in the CTNS Gene, and Potential for Repair
}

\author{
Dries David $^{a}$ b Sante Princiero Berlingerio ${ }^{b}$ Mohamed A. Elmonem ${ }^{c}$ \\ Fanny Oliveira Arcolino ${ }^{b}$ Neveen Soliman ${ }^{d}$ Bert van den Heuvel ${ }^{b}$ Rik Gijsbers ${ }^{a}$ \\ Elena Levtchenko ${ }^{b}$ e
}

\begin{abstract}
a Department of Pharmaceutical and Pharmacological Sciences, Laboratory for Viral Vector Technology and Gene Therapy, KU Leuven, Leuven, Belgium; ${ }^{b}$ Department of Development and Regeneration, Organ Systems Cluster, KU Leuven, Leuven, Belgium; ' Department of Clinical and Chemical Pathology, Faculty of Medicine, Cairo University, Cairo, Egypt; ${ }^{\mathrm{d}}$ Department of Pediatrics, Centre of Pediatric Nephrology and Transplantation, Kasr Al Ainy School of Medicine, Cairo University, Cairo, Egypt; ${ }^{e}$ Department of Pediatric Nephrology, UZ Leuven, Leuven, Belgium
\end{abstract}

\section{Keywords}

Cystinosis · Mutations · Geographic distribution

\begin{abstract}
Mutations in the CTNS gene encoding the lysosomal membrane cystine transporter cystinosin are the cause of cystinosis, an autosomal recessive lysosomal storage disease. More than 140 CTNS mutations have been reported worldwide. Recent studies have discovered that cystinosin exerts other key cellular functions beyond cystine transport such as regulation of oxidative state, lysosomal dynamics and autophagy. Here, we review the different mutations described in the CTNS gene and the geographical distribution of incidence. In addition, the characteristics of the various mutations in relation to the functions of cystinosin needs to be further elucidated. In this review, we highlight the functional consequences of the different mutations in correlation with the clinical phenotypes. Moreover, we propose how this under-
\end{abstract}

\section{KARGER}

() 2018 S. Karger AG, Basel

E-Mail karger@karger.com

www.karger.com/nef standing would be fundamental for the development of new technologies through targeted gene therapy, holding promises for a possible cure of the kidney and extra-renal phenotypes of cystinosis.

(c) 2018 S. Karger AG, Basel

\section{Clinical Presentation of Cystinosis}

Cystinosis is an autosomal recessive disease caused by mutations in the CTNS gene encoding the lysosomal membrane transporter cystinosin [1]. Cystinosin is a ubiquitously expressed protein, functioning as a cystine-proton co-transporter and extruding cystine out of the lysosomes; this activity is dependent on the lysosomal acidification conveyed by the $\mathrm{H}^{+}$-ATPase [2]. Cysti-

D.D. and S.P.B. equal contribution.
Prof. Elena Levtchenko

Department of Pediatric Nephrology, University Hospital Leuven Herestraat 49, Box 817 BE-3000 Leuven (Belgium)

E-Mail elena.levtchenko@uzleuven.be 
nosin deficiency results in lysosomal cystine accumulation and cystine crystals formation in virtually all tissues and organs [3]. While cystinosis belongs to a larger group of $\sim 50$ lysosomal storage disorders, mostly caused by lysosomal enzyme deficiencies, its clinical phenotype is distinct, with the kidney being the first affected organ.

Depending on kidney disease severity, the cystinosis phenotype is divided in 3 clinical forms [4]. The most severe variant, infantile nephropathic cystinosis (MIM219800) affects $~ 95 \%$ of patients and is characterized by the development of renal Fanconi syndrome during the first months of life followed by glomerular dysfunction, which if untreated, results in end-stage kidney disease (ESKD) around the age of 10 years. Late-onset juvenile nephropathic type (MIM219900) usually presents during childhood or at adolescence with mild or even absent proximal tubular dysfunction, proteinuria, which can be in the nephrotic range, and a slower rate of progression towards ESKD [5]. Non-nephropathic cystinosis (MIM219750) is a benign variant presenting with photophobia due to cystine accumulation in the cornea but causing no systemic organ damage [6].

All 3 clinical forms of cystinosis are due to bi-allelic mutations in the CTNS gene with a mutation detection rate $>95 \%$ [7].

The first two clinical phenotypes of cystinosis are also characterized by extra-renal organ dysfunction gradually developing from childhood to adulthood. The eye is the second affected organ with cystine crystals found in the cornea and retina early in life, and progressive retinopathy eventually leading to blindness at adolescence or adult age [8]. Endocrine organs (thyroid, pancreas, and gonads), GI tract, muscles, bones, central and peripheral nervous systems are also impacted by the disease, with morbidity and mortality frequently being associated with the swallowing dysfunction and aspiration due to muscle weakness [9].

Long-term prognosis of patients with cystinosis has dramatically improved during the last 30 years by the availability of the cystine-depleting drug cysteamine and advances of kidney transplantation. Cysteamine, a small amino thiol, was first introduced for the treatment of cystinosis in 1976 [10] and later was shown to prolong kidney function survival, improve growth, and delay or even prevent extra-renal disease complications $[11,12]$. The results of kidney transplantation in cystinosis are excellent with no disease recurrence and long-term graft survival being better in cystinosis compared to other renal disease patients $[13,14]$. Hence, the oldest cystinosis pa- tients passed now the age of 55, and a new generation of well-treated patients is expected to have even better life expectancy. Nevertheless, the severity of renal Fanconi syndrome with daily urine volume sometimes exceeding $10 \mathrm{~L}$ and resistance to cysteamine therapy, multiorgan involvement in cysteamine-treated patients, and the burden of cysteamine administration causing unpleasant body and breath odour, GI and bone complaints in some patients, point out the necessity of developing novel, less toxic and more efficient treatment strategies tackling all disease aspects.

\section{Genetic Basis of Cystinosis}

\section{Overview of Mutations in the CTNS Gene and} Geographical Distribution

Over 140 pathogenic CTNS mutations have been reported in cystinosis patients worldwide. These include 57 missense and nonsense mutations, 23 intronic mutations, 45 deletions, 13 small insertions, 4 indels and 3 promoter region mutations (Table 1) [15]. Overall, there is a considerable genotype-phenotype correlation of the CTNS mutations, with the absolute majority of pathogenic mutations causing the infantile phenotype, while only 15 and 4 mutations have been attributed to juvenile and ocular cystinosis respectively (Table 1 ).

Most reported CTNS mutations were detected in countries of Europe and North America, with only a minority of developing nations conducting genetic studies, mostly due to lacking funds to perform molecular diagnosis in potential patients [16]. Notably over the last decade, an increasing number of reports have been published on CTNS gene mutations in some of the developing nations' populations [17-20]. Still, large geographic regions, such as sub-Saharan Africa, South-East Asia and the Far East are underrepresented in the genetic spectrum of their cystinosis patients. Although accurate statistics are lacking in the developing world [21], recent studies from the Middle East [17-20], Mexico [22] and South Africa [23] may indicate that the incidence of cystinosis in many of these countries is expected to be higher than that of Europe and North America. Moreover, many cystinosis patients in poor countries remain undiagnosed and die at a young age due to complications of the disease [24].

The genetic landscape of cystinosis varies widely based on the ethnic and genetic makeup of each reporting population. The most common pathogenic mutations in Northern Europe and North America is a large 
Table 1. Geographical distribution of all reported mutations in the CTNS gene

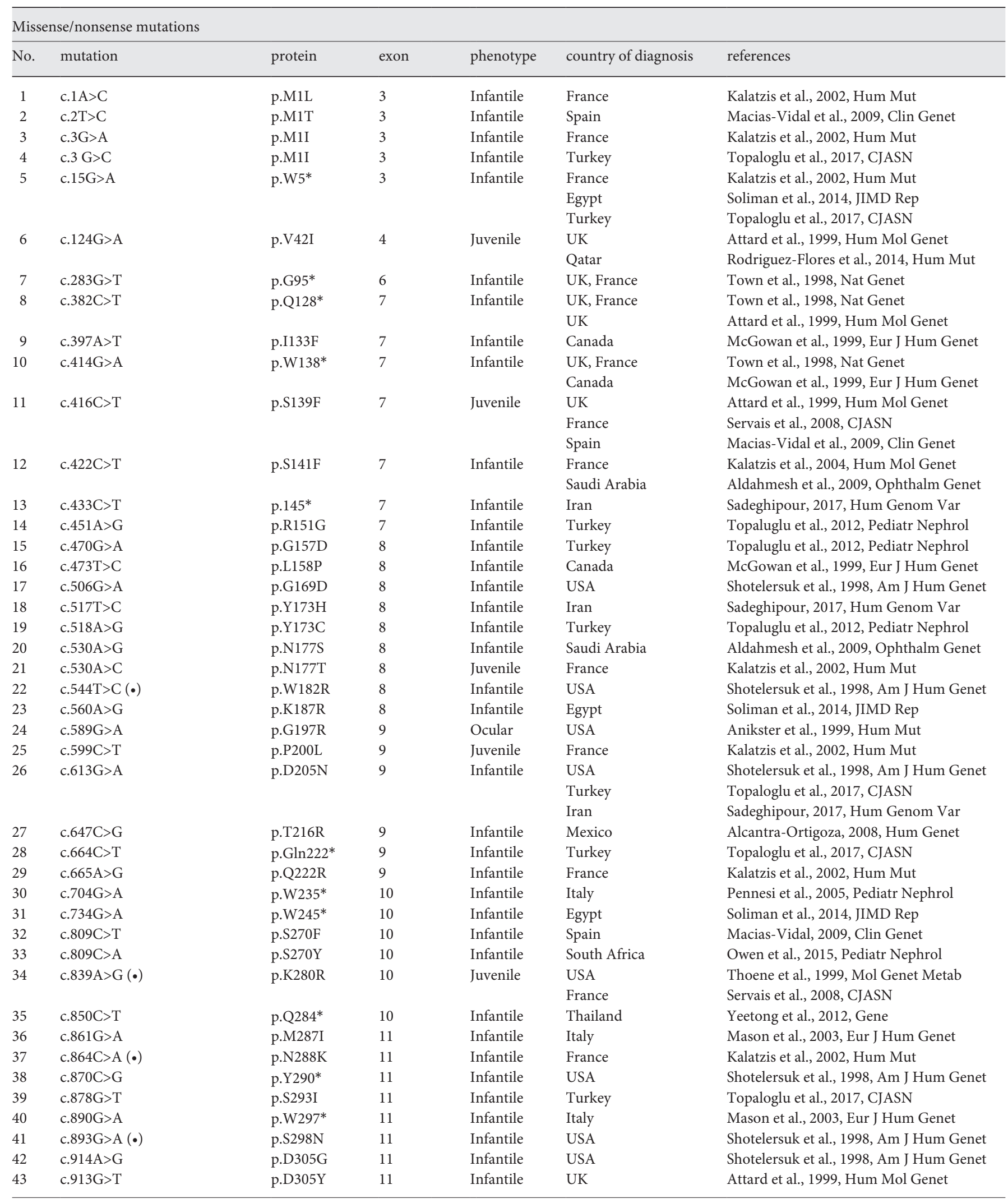


Table 1. (continued)

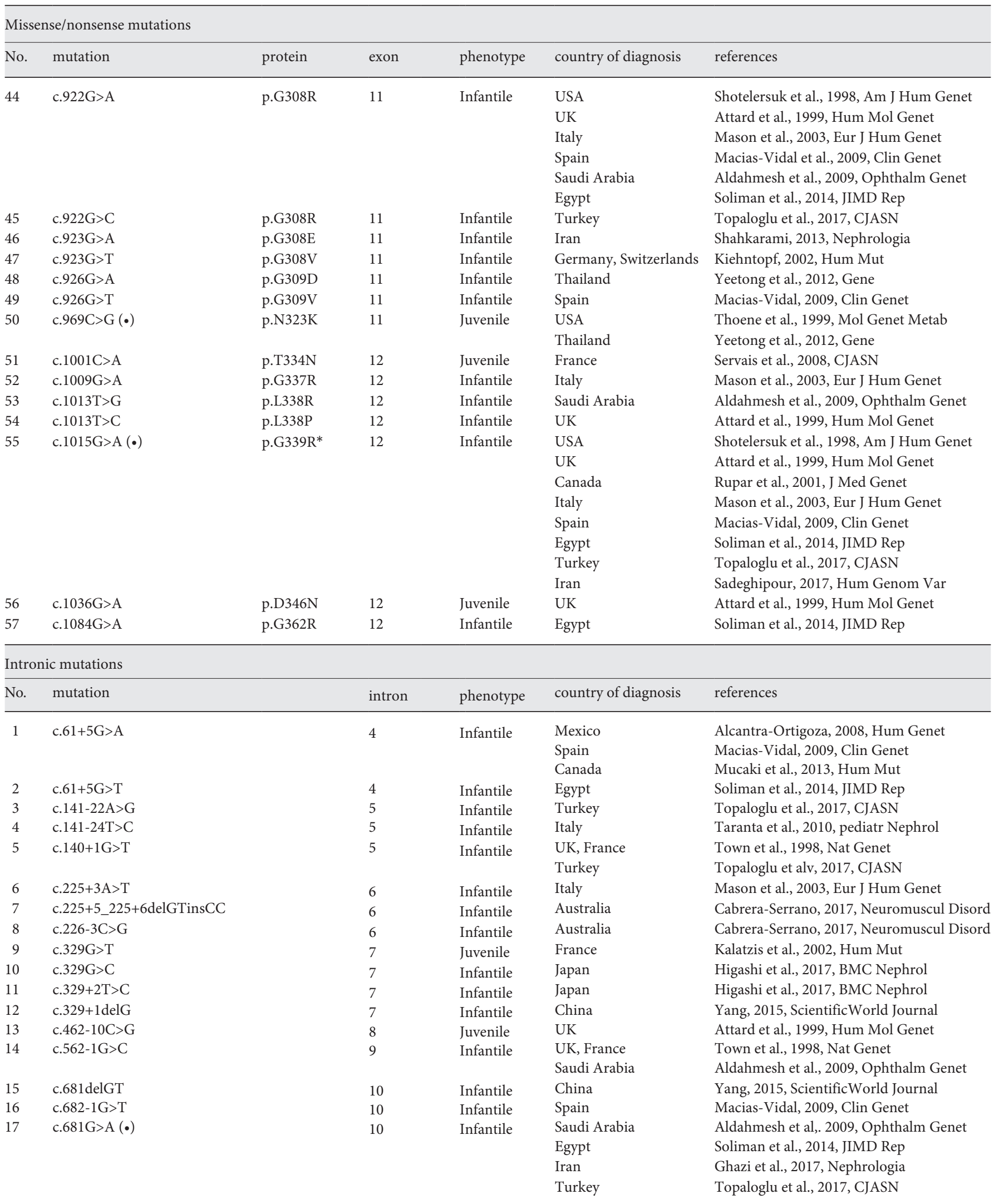


Table 1. (continued)

\begin{tabular}{|c|c|c|c|c|c|c|}
\hline \multicolumn{7}{|c|}{ Intronic mutations } \\
\hline \multirow{3}{*}{$\begin{array}{l}\text { No. } \\
18\end{array}$} & \multicolumn{2}{|l|}{ mutation } & intron & \multirow{3}{*}{$\begin{array}{l}\text { phenotype } \\
\text { Infantile }\end{array}$} & \multirow{3}{*}{$\begin{array}{l}\text { country of diagnosis } \\
\text { UK } \\
\text { Italy }\end{array}$} & \multirow{3}{*}{$\begin{array}{l}\text { references } \\
\text { Attard et al., 1999, Hum Mol Genet } \\
\text { Mason et al., 2003, Eur J Hum Genet }\end{array}$} \\
\hline & c. $681+1 G>A$ & 10 & & & & \\
\hline & & & & & & \\
\hline \multirow[t]{2}{*}{19} & c. $853-3 \mathrm{C}>\mathrm{G}$ & 11 & & Ocular & USA & Anikster et al., 1999, Hum Mut \\
\hline & & & & & Russia & Bryzgalov, 2013, PLoS One \\
\hline 20 & c. $853-2 \mathrm{~A}>\mathrm{G}$ & 11 & & Infantile & France & Kalatzis et al., 2002, Hum Mut \\
\hline 21 & c. $853-1 \mathrm{G}>\mathrm{A}$ & 11 & & Infantile & Turkey & Topaloglu et al., 2017, CJASN \\
\hline \multirow[t]{4}{*}{22} & c.971-12G>A $(\bullet)$ & 12 & & Infantile & $\mathrm{UK}$ & Attard et al., 1999, Hum Mol Genet \\
\hline & & & & & Thailand & Yeetong et al., 2012, Gene \\
\hline & & & & & South Africa & Owen et al., 2015, Pediatr Nephrol \\
\hline & & & & & Iran & Sadeghipour, 2017, Hum Genom Var \\
\hline 23 & c. $970+2 \mathrm{~T}>\mathrm{C}$ & 12 & & Juvenile & USA & Thoene et al., 1999, Mol Genet Metab \\
\hline \multicolumn{7}{|c|}{ Promoter mutations } \\
\hline No. & position & & & phenotype & country of diagnosis & references \\
\hline \multirow[t]{2}{*}{1} & \multirow{2}{*}{\multicolumn{3}{|c|}{$-295 \mathrm{G}>\mathrm{T}$ ( -50 relative to transcription initiation site) }} & Infantile & USA & Phornphutkul et al., 2001, Am J Hum Genet \\
\hline & & & & & Italy & Mason et al., 2003, Eur J Hum Genet \\
\hline 2 & \multirow{2}{*}{\multicolumn{3}{|c|}{$\begin{array}{l}-295 \text { ins } \mathrm{T}(-50 \text { relative to transcription initiation site }) \\
-303 \mathrm{G}>\mathrm{C}(-42 \text { relative to transcription initiation site) }\end{array}$}} & Ocular & USA & Phornphutkul et al., 2001, Am J Hum Genet \\
\hline 3 & & & & Ocular & USA & Phornphutkul et al., 2001, Am J Hum Genet \\
\hline \multicolumn{7}{|c|}{ Deletions } \\
\hline No. & mutation & protein & exon & phenotype & country of diagnosis & references \\
\hline \multirow[t]{9}{*}{1} & \multirow[t]{9}{*}{ c.18_21delGACT } & \multirow[t]{9}{*}{ T7Ffs*7 } & \multirow[t]{9}{*}{3} & \multirow[t]{9}{*}{ Infantile } & UK, France & Town et al., 1998, Nat Genet \\
\hline & & & & & Netherlands & Heil et al., 2001, Nephron \\
\hline & & & & & Italy & Mason et al., 2003, Eur J Hum Genet \\
\hline & & & & & Mexico & Alcantra-Ortigoza, 2008, Hum Genet \\
\hline & & & & & France & Servais et al., 2008, CJASN \\
\hline & & & & & Spain & Macias-Vidal, 2009, Clin Genet \\
\hline & & & & & Thailand & Yeetong et al., 2012, Gene \\
\hline & & & & & Iran & Shahkarami, 2013, Nephrologia \\
\hline & & & & & Turkey & Topaloglu et al., 2017, CJASN \\
\hline 2 & c.36delT & L14* & 3 & Infantile & UK, France & Town et al., 1998, Nat Genet \\
\hline 3 & c.40delC & L14* & 3 & Infantile & Mexico & Alcantra-Ortigoza, 2008, Hum Genet \\
\hline 4 & c.60_61delTG & Splicing & & & UK, France & Town et al., 1998, Nat Genet \\
\hline 5 & c.61_61+2delGGT & Splicing & & & Germany, Switzerlands & Kiehntopf, 2002, Hum Mut \\
\hline 6 & c.120delC & N41Tfs*10 & 4 & Infantile & Iran & Ghazi et al., 2017, Nephrologia \\
\hline 7 & c.198_218del21 (•) & ITILELP67-73del & 5 & Juvenile & USA & Shotelersuk et al., 1998, Am J Hum Genet \\
\hline 8 & c.206_210delTCCTT & I69Rfs*5 & 5 & Infantile & USA & Shotelersuk, 1998, Am J Hum Genet \\
\hline 9 & c. $225+5 \_225+8$ delGTAA & Splicing & & & France & Kalatzis et al., 2002, Hum Mut \\
\hline 10 & c.257_258delCT & S86Ffs*38 & & & Iran & Ghazi et al., 2017, Nephrologia \\
\hline 11 & c.260_261delTT & F87Sfs*37 & 6 & Infantile & Egypt & Soliman et al., 2014, JIMD Rep \\
\hline 12 & c.280delG & V94Lfs*24 & 6 & Infantile & Germany, Switzerlands & Kiehntopf, 2002, Hum Mut \\
\hline 13 & c.291_294delTACT & T98Ffs*19 & 6 & Infantile & Turkey & Topaloglu et al., 2017, CJASN \\
\hline 14 & c.295_310del16 & V99Ifs*14 & 6 & Infantile & Spain & Macias-Vidal, 2009, Clin Genet \\
\hline 15 & c.314_317delACTC & H105Pfs*12 & 6 & Infantile & USA & Shotelersuk, 1998, Am J Hum Genet \\
\hline 16 & c.320_323delATCA & N107Rfs*10 & 6 & Infantile & Spain & Macias-Vidal, 2009, Clin Genet \\
\hline 17 & c.323delA & Q108Rfs*10 & 6 & Infantile & Iran & Ghazi et al., 2017, Nephrologia \\
\hline 18 & c.325_329del & Splicing & 6 & Infantile & Turkey & Doneray, 2017, Eurasian J Med \\
\hline 19 & c. 423 delC & F142Sfs*5 & 7 & Infantile & $\mathrm{UK}$ & Attard et al., 1999, Hum Mol Genet \\
\hline 20 & c.492_515del24 & FVALNLTGdel162-169 & 8 & Infantile & Iran & Sadeghipour, 2017, Hum Genom Var \\
\hline 21 & c.518_519delAC & Y173* & 8 & Infantile & Spain & Macias-Vidal, 2009, Clin Genet \\
\hline 22 & c.519_520delCA & Y173* & 8 & Infantile & UK, France & Town et al., 1998, Nat Genet \\
\hline
\end{tabular}


Table 1. (continued)

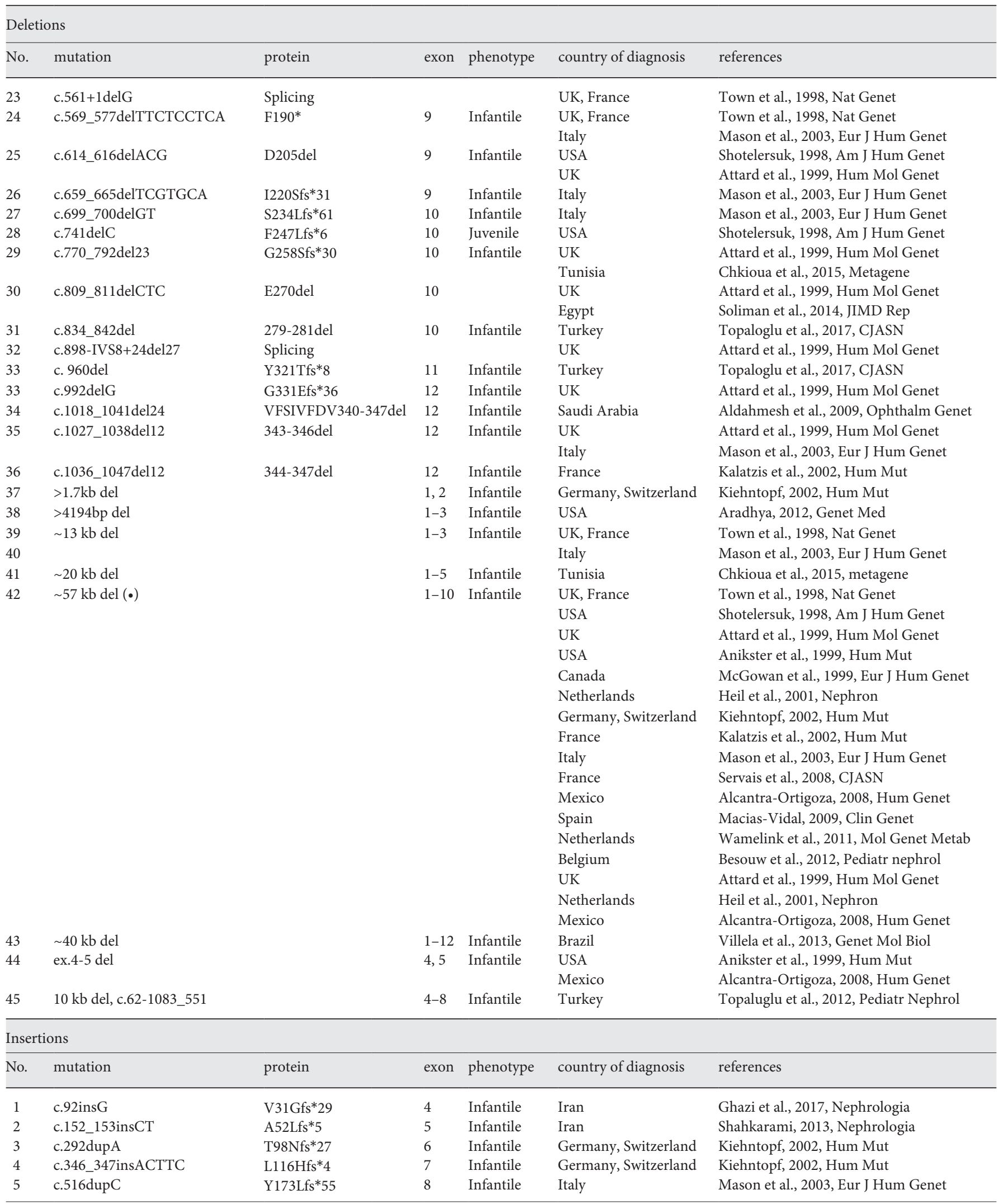


Table 1. (continued)

\begin{tabular}{|c|c|c|c|c|c|c|}
\hline \multicolumn{7}{|c|}{ Insertions } \\
\hline No. & mutation & protein & exon & phenotype & country of diagnosis & references \\
\hline 6 & c.577_578insA & N196Kfs*32 & 9 & Infantile & Greece & Bitsori et al., 2018, CEN Case rep \\
\hline \multirow[t]{5}{*}{7} & c.646dupA & T216Nfs*12 & 9 & Juvenile & USA & Shotelersuk, 1998, Am J Hum Genet \\
\hline & & & & & UK & Attard et al., 1999, Hum Mol Genet \\
\hline & & & & & Mexico & Alcantra-Ortigoza, 2008, Hum Genet \\
\hline & & & & & France & Servais et al., 2008, CJASN \\
\hline & & & & & Spain & Macias-Vidal, 2009, Clin Genet \\
\hline 8 & c.661ins T & Q222Afs*6 & 9 & Infantile & Iran & Ghazi et al., 2017, Nephrologia \\
\hline \multirow[t]{2}{*}{9} & c.696_697dupCG & V233Rfs*21 & 10 & Infantile & USA & Shotelersuk, 1998, Am J Hum Genet \\
\hline & & & & & $\mathrm{UK}$ & Attard et al., 1999, Hum Mol Genet \\
\hline \multirow[t]{4}{*}{10} & c.696dupC & V233Rfs*63 & 10 & Infantile & USA & Shotelersuk, 1998, Am J Hum Genet \\
\hline & & & & & $\mathrm{UK}$ & Attard et al., 1999, Hum Mol Genet \\
\hline & & & & & Canada & McGowan, 1999, Eur J Hum Genet \\
\hline & & & & & Italy & Mason et al., 2003, Eur J Hum Genet \\
\hline \multirow[t]{3}{*}{11} & c.829dupA & T277Nfs*19 & 10 & Infantile & Belgium & Besouw et al., 2012, Pediatr nephrol \\
\hline & & & & & Egypt & Soliman et al., 2014, JIMD Rep \\
\hline & & & & & Turkey & Topaloglu et al., 2017, CJASN \\
\hline \multirow[t]{2}{*}{12} & c.926dupG & S310Qfs*55 & 11 & Infantile & USA & Shotelersuk, 1998, Am J Hum Genet \\
\hline & & & & & Netherlands & Heil et al., 2001, Nephron \\
\hline 13 & c.1047_1048ins12 & DVEF349-350ins & 12 & Infantile & France & Kalatzis et al., 2002, Hum Mut \\
\hline \multicolumn{7}{|c|}{ Indels } \\
\hline No. & mutation & protein & exon & phenotype & country of diagnosis & references \\
\hline 1 & c.225+5_225+6delGTinsCC & Splicing & & Infantile & USA & Anikster et al., 1999, Hum Mut \\
\hline 2 & c.751_754delACCAinsCG & T251Rfs*44 & 10 & Juvenile & Mexico & Alcantra-Ortigoza, 2008, Hum Genet \\
\hline 3 & c.1028_1035delTCGTCTTCinsA & $\mathrm{I} 343 \mathrm{Kfs} * 22$ & 12 & Infantile & USA & Shotelersuk et al., 1998, Am J Hum Genet \\
\hline 4 & c.1032delCinsTG & F345Vfs*20 & 12 & Infantile & Egypt & Soliman et al., 2014, JIMD Rep \\
\hline
\end{tabular}

Table is updated up to July 2018 and adapted from citation [15].

$(\bullet)$, mutations cited in the text; ${ }^{*}$ data based on public HGMD database.

deletion (57-kb del) [12] affecting the promoter region and the first 10 exons of the CTNS gene together with 2 upstream genes (CARKL and TRPV1) [25]. This deletion represents over $50 \%$ of mutant alleles in cystinosis patients of Northern European ancestry; however, it is completely absent in all reported patients from the Middle East, Asia and Africa [16], suggesting a founder mutation. Other important founder mutations can be encountered in certain populations or certain geographic loci, such as the c.1015G $>\mathrm{A}$ in the Amish population in Western Ontario, Canada [26], the c.971-12G $>A$ in the black population of South Africa [23] and the c.681G>A in the Middle East [17-19]. A more detailed description of the genetic map of cystinosis is needed to elucidate the similarities and the differences between patients all over the world and to prepare for individualized disease treatment targeting gene repair.

Geographic Distribution and Functional Consequences of Mutations in CTNS Gene
Functional Characteristics of CTNS Mutations: Genotype-Phenotype Correlations

CTNS is a lysosomal 7-transmembrane protein (Fig. 1), which functions as $\mathrm{H}^{+}$-driven cystine transporter [2]. It is predicted to have $7 \mathrm{~N}$-glycosylation sites located at the $\mathrm{N}$ terminal tail, residing in the lysosomal lumen. Two lysosomal targeting motifs, YFPQA (5th inter-transmembrane loop) and GYDQL (C-terminal tail), ensure localization to the lysosome [27]. An alternative splice variant termed CTNS-LKG exists, resulting in a longer protein (400 vs. 367 amino acids) with a plasma membrane targeting signal SSLKG replacing the C-terminal GYDQL [28, 29].

Kalatzis et al. [30] have studied the functional consequences of 31 CTNS mutations using constructs that encoded CTNS lacking the GYDQL lysosomal targeting signal, termed CTNS- $\triangle$ GYDQL. This truncation leads to a 


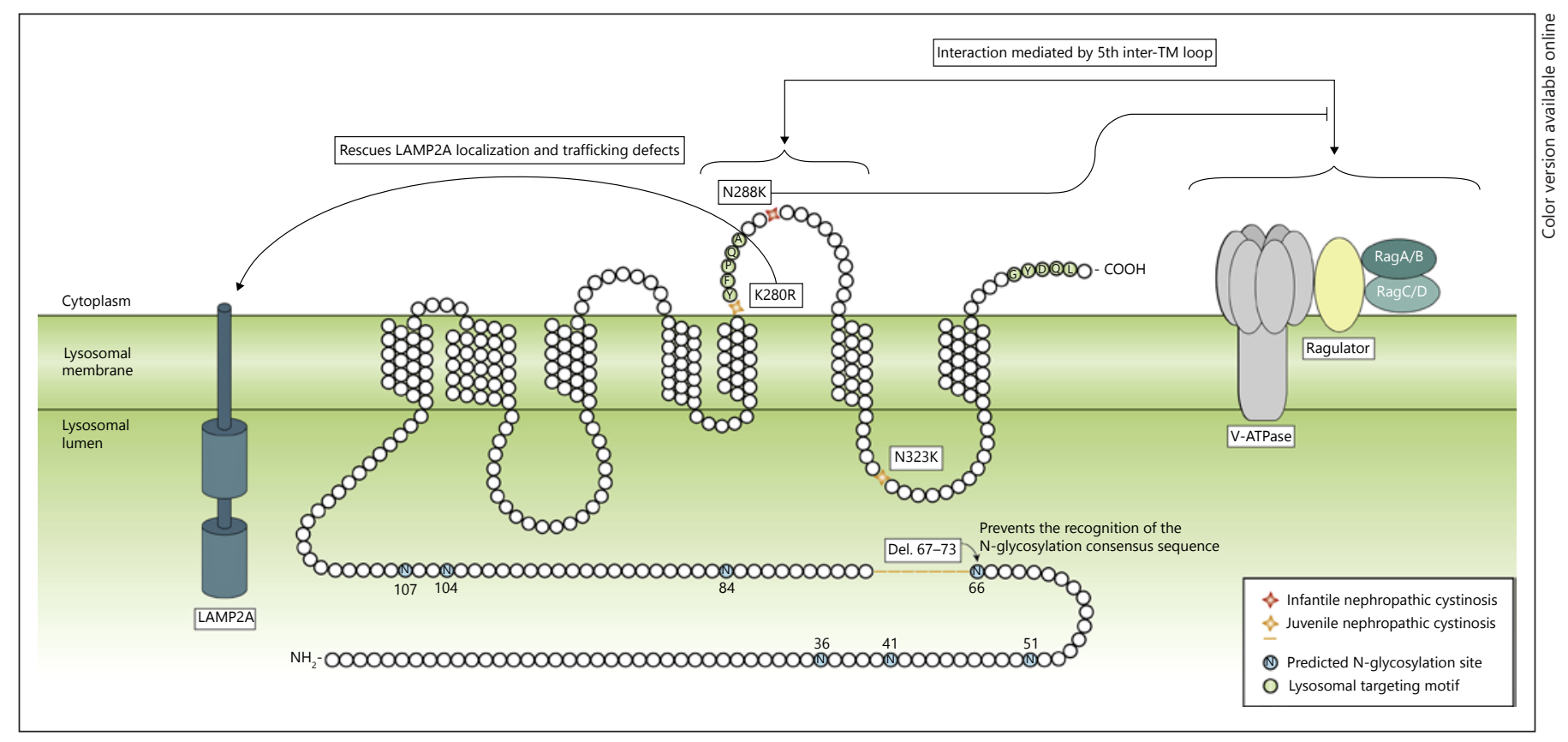

Fig. 1. Structure of cystinosin with indication of CTNS mutations having an effect on LAMP2A localization [36, 37], interaction with V-ATPase-Ragulator-Rag complex and glycosylation status [33].

translocation of the cystinosin protein to the plasma membrane, thus enabling the monitoring of extracellular $\left[{ }^{35} \mathrm{~S}\right]$-cystine influx. In particular, they measured the transport activity compared with WT CTNS in a COS-7 cell transfection model. Surprisingly, it was found that specific CTNS mutations (e.g., CTNS ${ }^{\mathrm{S} 298 \mathrm{~N}}$ and $\mathrm{CTNS}^{\mathrm{W} 182 \mathrm{R}}$ ) causing infantile nephropathic cystinosis, retained cystine transport activity. Conversely, mutations (e.g., $\mathrm{CTNS}^{\mathrm{N} 323 \mathrm{~K}}$ and $\mathrm{CTNS}^{\mathrm{K} 280 \mathrm{R}}$ ) resulting in juvenile nephropathic cystinosis, lost cystine transport activity [30]. These findings opposed the well-accepted paradigm that cystine accumulation is the primary pathogenic cause of cystinosis and suggested that CTNS exerts other key functions beyond cystine transport $[2,30]$. Supporting these findings, cysteamine treatment does not alleviate the complete phenotype of cystinosis.

Indeed, other CTNS functions are being investigated, involving cell-survival pathways and the mammalian target of rapamycin complex 1 (mTORC1) activity. mTORC1 is the master regulator of cell growth, which is recruited to the lysosomal membrane in presence of nutrients, activating protein translation and inhibiting autophagy. Conversely, upon starvation, mTORC1 released from the lysosomal surface is inactivated, leading to the upregulation of autophagy and inhibition of the main anabolic pathways [31, 32]. Recently, CTNS was found to be part of the V-ATPase-Ragulator-Rag complex, which controls mTORC1 activation [33]. Both mutations CTN$\mathrm{S}^{\mathrm{N} 323 \mathrm{~K}}$ and $\mathrm{CTNS}{ }^{\mathrm{K} 280 \mathrm{R}}$ did not show any alteration in the interaction of mTORC1 with cystinosin. However, this was not true for $\mathrm{CTNS}^{\mathrm{N} 288 \mathrm{~K}}$, which specifically resulted in infantile nephropathic cystinosis with loss of cystine transport activity [33] (Table 2). Moreover, mouse Ctns ${ }^{-/-}$ proximal tubular cells showed disturbed mTORC1 signalling and delayed docking of mTORC1 to the lysosomal surface following the re-introduction of the complete medium after starvation [5]. In addition, human cystinotic proximal tubular cells carrying the $57 \mathrm{~kb}$ deletion and a compound heterozygous (c.Y173X+p.G339R) showed abnormal lysosomal mTORC1 localization upon starvation, and cysteamine supplementation did not rescue the phenotype [34].

When mTORC1 is recruited to the lysosomal membrane, it also phosphorylates and inhibits transcription factor EB (TFEB). TFEB normally activates lysosomal biogenesis and autophagy-related genes, in response to starvation [32]. Human $\mathrm{CTNS}^{-/-}$proximal tubular epithelial cells (PTEC) showed lower TFEB expression, which was mainly located in the nucleus. Overexpressing TFEB in CTNS $^{-/-}$PTEC rescued some of the CTNS WT characteristic such as (i) delayed lysosomal cargo processing, (ii) improved morphological irregularities of the 
Table 2. CTNS mutations and their corresponding phenotype, cystine transport activity, location and other studied effects

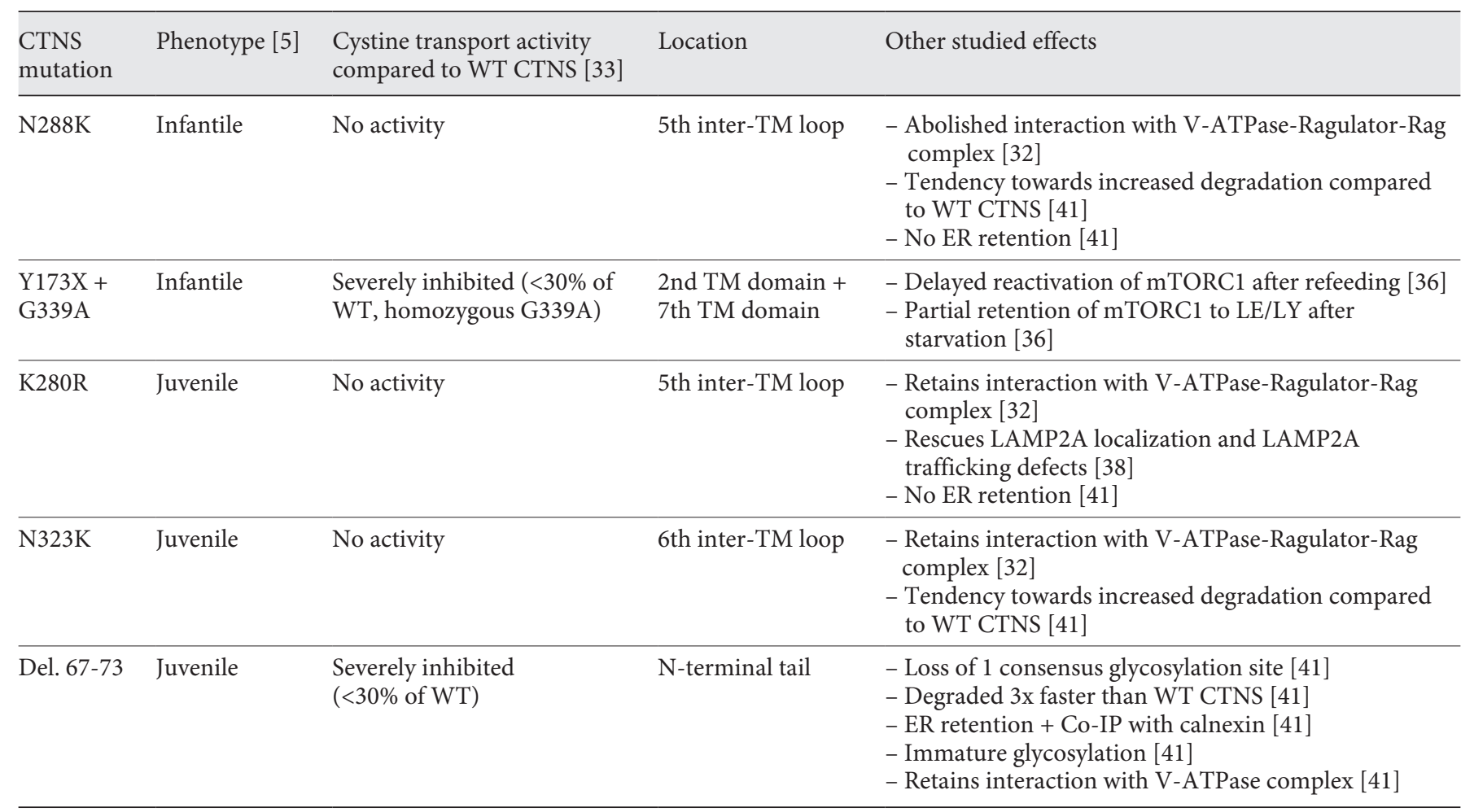

WT, wild type; LE/LY, late endosome/lysosome; ER, endoplasmic reticulum; TM, transmembrane.

lysosomal compartments (after $>24 \mathrm{~h}$ ) and (iii) promoted clearance of lysosomal cystine by exocytosis [35]. It would be interesting to investigate whether overexpressing (mutant and WT) CTNS in $\mathrm{CTNS}^{-/}$PTEC could rescue this defect, as this could further confirm the altered mTORC1 signalling shown in $\mathrm{Ctns}^{-/-}$proximal tubular cells.

Another role of CTNS, in addition to its potential involvement in mTORC1 signalling, is the altered chaperone mediated autophagy, as shown by two studies from Napolitano et al. [37] and Zhang et al. [36]. They observed impaired chaperone mediated autophagy (CMA) in cystinotic mouse skin fibroblasts presenting dislocation of LAMP2A (CMA receptor) and accumulation of GAPDH (CMA substrate). Interestingly, the CTNS $280 \mathrm{R}$ mutation rescued the localization of LAMP2A in contrast to cysteamine treatment. This was also true for CTNS-LKG, which is an alternative splice variant of CTNS, primarily targeted to the plasma membrane and other lysosomal/endosomal vesicles. Based on these results, it was suggested that CTNS is a necessary cofactor for LAMP2A trafficking [36, 37].
The lack of cystine transport activity of the CTNS ${ }^{\mathrm{K} 280 \mathrm{R}}$ and CTNS ${ }^{\mathrm{N} 288 \mathrm{~K}}$ mutants may be explained by the fact that both mutations are located at the 5th inter-transmembrane loop containing the PQ motif, which is required for $\mathrm{H}^{+}$and cystine co-transport [38]. The difference in clinical presentation, juvenile versus infantile cystinosis for CTNS ${ }^{\mathrm{K} 280 \mathrm{R}}$ and $\mathrm{CTNS}^{\mathrm{N} 288 \mathrm{~K}}$, respectively, can thus be only explained by effects beyond cystine transport.

As mentioned earlier, CTNS is predicted to have 7 $\mathrm{N}$-glycosylation sites at the $\mathrm{N}$-terminal tail (Fig. 1). $\mathrm{CTNS}^{\mathrm{N} 323 \mathrm{~K}}$ and $\mathrm{CTNS}^{\mathrm{N} 288 \mathrm{~K}}$ do not affect glycosylation of CTNS. However, a deletion of 7 amino acids at the $\mathrm{N}$-terminus, referred to as $\mathrm{CTNS}^{\text {Del.67-73 }}$ (juvenile nephropathic cystinosis with severely inhibited cystine transport), results in the loss of 1 consensus N-glycosylation site. Furthermore, this mutant protein degraded threefold faster than WT CTNS and was partially retained at the endoplasmic reticulum. Nevertheless, CTNS ${ }^{\text {Del.67-73 }}$ still interacts with the V-ATPase complex, which could explain the less severe phenotype caused by this mutation [39]. 


\section{Animal Models of Cystinosis}

\section{Mouse}

Sixteen years ago, Antignac's group generated the first model of cystinosis in $\mathrm{FVB} / \mathrm{N}$ mice by using promoter trap approach to eliminate the CTNS gene [40]. Although the model showed ocular abnormalities, bone defects, behavioural anomalies and partial response to cysteamine treatment, it presented a moderate cystine accumulation compared to the affected humans without any sign of morphological or functional alterations of the proximal tubule. As the genetic background can influence the renal phenotype, the same group developed a second model in C57BL/6 mouse, and observed mild proximal tubulopathy (without the urinary loss of amino acids, bicarbonates or sodium) and focal tubular lesions. However, no podocyte damage was present [41]. The latter mouse model has been widely used by different research groups for studying the pathogenesis and treatment strategies in cystinosis $[42,43]$.

\section{Yeast}

Saccharomyces cerevisiae is a well-established model organism, mainly used for genetic manipulations and biochemical analyses. ERS1, the yeast orthologous counterpart of the human CTNS gene, encodes for the Ers1 protein ( $28 \%$ identical $/ 46 \%$ similar to human CTNS), which localizes to the endosomes and the vacuole. ers $1 \Delta$ mutant shows hygromycin B (hygB) sensitivity, which could be reversed only by the complementation of a functional CTNS human gene [44] or by overexpressing $M E H 1$, which encodes a protein involved in vacuolar acidification and general amino acid permease (Gaplp) localization [44, 45]. Interestingly, Simpkins et al. [46] showed that Ers1 acts as a cystine transporter; however, the ers $1 \Delta$ mutant does not show any detectable defect in growth and has no cystine accumulation [44], thereby supporting the evidence that other genes could compensate for its lost function [46]. Another relevant study performed in yeast confirmed that the GYQDL signature at the C-terminal end is essential for the trafficking of cystinosin; indeed, deleting the GYQDL C-terminal region of CTNS expressed in yeast delocalized cystinosin from the vacuole to the plasma membrane, restoring the ability to grow on cystine [47]. As the developed CTNS- $\triangle$ GYDQL transformants showed low cystine uptake, vacuolar protein-sorting deletions have been developed to increase the protein concentration at the plasma membrane, from which 2 deletions stand out: $v s p 1 \Delta$, $v s p 17 \Delta$ enhancing the uptake levels. Several gain-of-function mutants were iso- lated, including 1 patient mutation, G197R. These data demonstrate that cystine-uptake assay in yeast cells is useful to decipher the functionality of mutant cystinosin proteins.

\section{Zebrafish}

Zebrafish is the most recent model organism to study cystinosis. Carrying the homozygous nonsense mutation in exon 8 of the $c t n s$, zebrafish larvae demonstrated early cystine accumulation, enhanced deformity, apoptosis and increased mortality, which are partially responsive to cysteamine treatment [48]. Furthermore, the model is characterized by impaired glomerular permselectivity and defective tubular reabsorption. Unlike the murine model, the adult $\mathrm{ctns}^{-/-}$zebrafish kidney accumulates the highest concentration of cystine. In line with functional abnormalities, increased lysosomal size and numbers characterize larvae's PTEC, while podocytes present partial foot process effacement and narrowed slit diaphragmatic space. This last phenotype is lacking in the mouse model, but is present in humans. The abundance and localization of the megalin receptor, is altered in $\mathrm{ctns}^{-/-}$larvae compared to WT, a marker for defective tubular reabsorption, which is not restored by cysteamine treatment. Hence, the zebrafish larval model closely copies the human kidney phenotype for cystinosis and is superior to all model organisms currently available. Therefore, it will be useful to further unravel the pathophysiological aspects of cystinosis and for the in vivo screening of novel therapeutic agents [48].

A comparison of cystinosis in humans, mice, yeast and zebrafish is presented in Table 3 (adapted from [48]).

\section{Future Perspective: Potential for Gene Repair}

To date, cysteamine is the only drug available to treat cystinosis. Although cysteamine can alleviate symptoms and delay disease progression, it does not prevent the Fanconi syndrome and renal transplantation is still necessary. In addition, compliance to cysteamine is low and side effects are frequently observed [49]. Thus, there is a need for novel therapies, which not only treat, but could potentially cure cystinosis.

Since cystinosis is a multi-systemic disease, developing gene therapy is challenging as all body cells require correction. In line with the strategy applied for other lysosomal storage disorders, Syres and colleagues transplanted bone marrow-derived cells and hematopoietic stem cells (HSC) from $\mathrm{Ctns}^{+/+}$to $\mathrm{Ctns}^{-/-}$mice [50]. The 
Table 3. Comparison of cystinosis in human, mouse, yeast and zebrafish

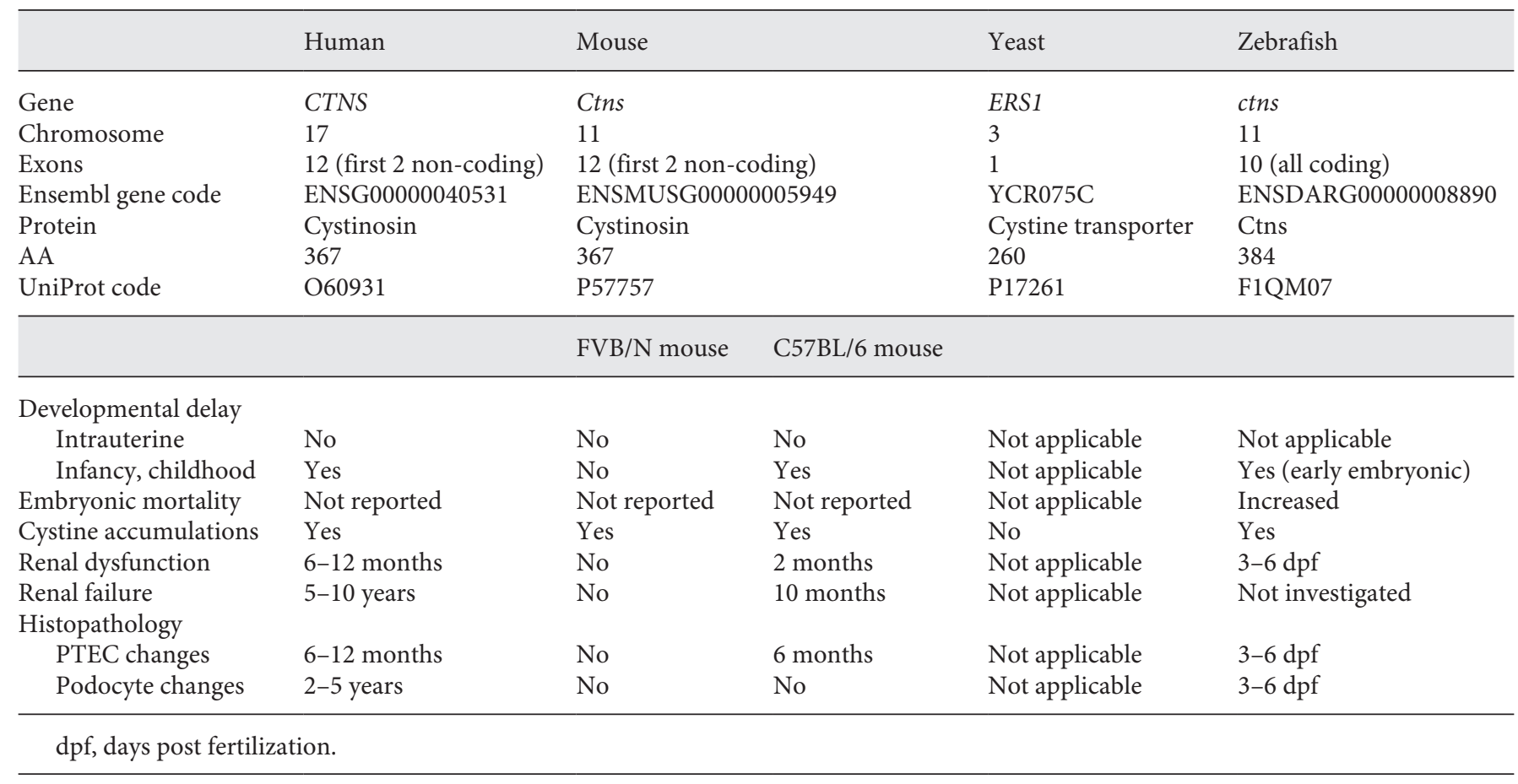

rationale underlying HSC therapy is that healthy donor cells migrate into the recipient's organs and release the missing protein locally, thereby correcting the metabolic defect [51]. However, for cystinosis it was still a question whether a transmembrane protein like CTNS could be taken up by the diseased cells [50]. In mice, bone marrow-derived cells and HSC-derived cells engrafted efficiently in the interstitial compartments of the kidney and other organs, decreased cystine accumulation and averted development of kidney dysfunction [50]. Moreover, if sufficient donor-derived blood cell engraftment took place ( $>50 \%$ of blood cells), the cystinotic phenotype was corrected up till 7-15 months post transplantation [52]. All together these findings provide a proof-ofprinciple that cystinotic mice can be treated by HSC transplantation. Elmonem et al. [53] reported the first human case which underwent allogenic HSC transplantation from a full HLA-matched unrelated donor. Although mRNA and cystinosin protein transfer from HSC to epithelial cells did occur and was able to reduce cystine crystal load, the patient still developed ESKD and died from severe graft-versus-host disease, as a complication of transplantation. Because of the inherent risks associated with allogenic transplantation, autologous $\mathrm{Ctns}^{-/-} \mathrm{HSC}$ transplantation of HSC corrected with a lentiviral vector encoding a functional copy of CTNS were evaluated in mice. This approach reduced cystine content in all tissues and improved kidney function in a mouse model of cystinosis [54]. In addition, cross correction of diseased cells was shown to be mediated by tunnelling nanotubes produced by the gene-corrected macrophages [54]. Both in vitro and in vivo, these tunnelling nanotubes provided diseased cells with functional CTNS bearing lysosomes. The transfer was found to be bi-directional as cystine loaded lysosomes from cystinotic cells were transferred to the macrophage as well [55].

With several gene therapeutic approaches reaching the market in the past years, gene therapy also holds promise to cure cystinosis. In line with this, the company Avrobio has planned to start Phase 1/2 human trials in 2019 (http://www.avrobio.com/pipeline/). However, the importance of CTNS expression levels should be noted as CTNS is regulated both at the transcriptional and the posttranscriptional level $[56,57]$. The promoter driving CTNS expression in lentiviral constructs should be evaluated carefully as overexpression of CTNS has been reported to enlarge lysosomal structures of which the long-term consequence is currently unknown $[27,54]$. Despite the promising results of gene therapy for other lysosomal 
storage disorders [58] long-term safety and efficacy of such therapy still require to be studied in more detail before it becomes a realistic option as a first-line treatment for patients affected by lysosomal storage disorders.

Due to the risks associated with HSC transplantation, especially in young children, researchers set out to find novel gene therapeutic approaches. Arcolino et al. [59] showed that urine of preterm neonates contained kidney stem/progenitor cells that had regenerative paracrine effect and could differentiate into podocytes and proximal tubule epithelial cells. Therefore, we hypothesize that, ex vivo gene-corrected autologous cystinosis kidney progenitors could also be used as source for cell therapy that could potentially cure the kidney phenotype. As cystinosis is a multisystemic disease, this therapy should be combined with drug therapy protecting extra-renal organs.

\section{Conclusion}

Worldwide pathogenic CTNS mutations have been reported in cystinosis patients, but still, well-documented incidence and geographical distribution has been poorly described. Analysis of mutant cystinosin has provided the research field with a new scientific consensus in which CTNS has other critical functions beyond cystine transport. However, the extent to which defects in these other functions contribute to the overall clinical phenotype still needs further investigation. Preclinical studies using different animal models might elucidate functional consequences of specific mutations and might pave the way for a more personalized treatment depending on the correlations between genotype and phenotype.

The results of treatment with cysteamine vary widely and studies showed that cysteamine improves the outcome of cystinosis but does not provide cure. Hence, there is a need to find alternative therapeutic strategies. Over the last decades, cystinosis evolved from a paediatric lethal to a treatable disorder, with the advent of gene- and cell therapy, cystinosis might even become curable.

\section{Ethics Statement}

The authors have no ethical conflicts to disclose.

\section{Disclosure Statement}

The authors have no conflicts of interest to declare.

\section{Funding Sources}

E.L. is supported by FWO (1801110N) and E-RARE (JTC2014). R.G is supported by FWO (G0B3516N). E.L., R.G., and S.P.B. are supported by $\mathrm{C} 1$ grant from KU Leuven. F.O.A. is supported by FWO (12Q9917N).

\section{Authors Contribution}

D.D., S.P.B., M.A.E., F.O.A., N.S., B.V.H., R.G., and E.L. searched the literature and wrote the review text. D.D., S.P.B., and M.A.E. prepared the figure and tables.

\section{References}

1 Town M, Jean G, Cherqui S, Attard M, Forestier L, Whitmore SA, Callen DF, Gribouval O, Broyer M, Bates GP, van't Hoff W, Antignac C: A novel gene encoding an integral membrane protein is mutated in nephropathic cystinosis. Nat Genet 1998;18:319-324.

2 Kalatzis V, Cherqui S, Antignac C, Gasnier B: Cystinosin, the protein defective in cystinosis, is a $\mathrm{H}(+)$-driven lysosomal cystine transporter. EMBO J 2001;20:5940-5949.

3 Gahl WA, Thoene JG, Schneider JA: Cystinosis. N Engl J Med 2002;347:111-121.

4 Schneider JA, Wong V, Bradley K, Seegmiller JE: Biochemical comparisons of the adult and childhood forms of cystinosis. N Engl J Med 1968;279:1253-1257.

5 Goldman H, Scriver CR, Aaron K, Delvin E, Canlas Z: Adolescent cystinosis: comparisons with infantile and adult forms. Pediatrics 1971;47:979-988.

6 Anikster Y, Lucero C, Guo J, Huizing M, Shotelersuk V, Bernardini I, McDowell G, Iwata F, Kaiser-Kupfer MI, Jaffe R, Thoene J, Schneider JA, Gahl WA: Ocular nonnephropathic cystinosis: clinical, biochemical, and molecular correlations. Pediatr Res 2000;47:17-23.

7 Levtchenko E, van den Heuvel L, Emma F, Antignac C: Clinical utility gene card for: cystinosis. Eur J Hum Genet 2014;22.

8 Kaiser-Kupfer MI, Caruso RC, Minkler DS, Gahl WA: Long-term ocular manifestations in nephropathic cystinosis. Arch Ophthalmol 1986;104:706-711.

9 Nesterova G, Gahl W: Nephropathic cystinosis: late complications of a multisystemic disease. Pediatr Nephrol 2008;23:863-878.
10 Thoene JG, Oshima RG, Crawhall JC, Olson DL, Schneider JA: Cystinosis. Intracellular cystine depletion by aminothiols in vitro and in vivo. J Clin Invest 1976;58:180189 .

11 Markello TC, Bernardini IM, Gahl WA: Improved renal function in children with cystinosis treated with cysteamine. N Engl J Med 1993;328:1157-1162.

12 Gahl WA, Balog JZ, Kleta R: Nephropathic cystinosis in adults: natural history and effects of oral cysteamine therapy. Ann Intern Med 2007; 147:242-250.

13 Van Stralen KJ, Emma F, Jager KJ, Verrina E, Schaefer F, Laube GF, Lewis MA, Levtchenko EN: Improvement in the renal prognosis in nephropathic cystinosis. Clin J Am Soc Nephrol 2011;6:2485-2491. 
14 Cohen C, Charbit M, Chadefaux-Vekemans B, Giral M, Garrigue V, Kessler M, Antoine C, Snanoudj R, Niaudet P, Kreis H, Legendre C, Servais A: Excellent long-term outcome of renal transplantation in cystinosis patients. Orphanet J Rare Dis 2015;10:90.

15 Ibrahim M: Cystinosis: New insights into pathophysiology and clinical implications.: Development and Regeneration, KU Leuven, $\mathrm{PhD}, 2018$.

16 Elmonem MA, Veys KR, Soliman NA, van Dyck M, van den Heuvel LP, Levtchenko E: Cystinosis: a review. Orphanet J Rare Dis 2016;11:47.

17 Soliman NA, Elmonem MA, van den Heuvel L, Abdel Hamid RH, Gamal M, Bongaers I, Marie S, Levtchenko E: Mutational spectrum of the CTNS gene in Egyptian patients with nephropathic cystinosis. JIMD Rep 2014;14: 87-97.

18 Aldahmesh MA, Humeidan A, Almojalli HA, Khan AO, Rajab M, AL-Abbad AA,, Meyer BF, Alkuraya FS: Characterization of CTNS mutations in Arab patients with cystinosis. Ophthalmic Genet 2009;30:185-189.

19 Shahkarami S, Galehdari H, Ahmadzadeh A, Babaahmadi M, Pedram M: The first molecular genetics analysis of individuals suffering from nephropatic cystinosis in the Southwestern Iran. Nefrologia 2013;33:308-315.

20 Topaloglu R, Vilboux T, Coskun T, Ozaltin F, Tinloy B, Gunay-Aygun M, Bakkaloglu A, Besbas N, van den Heuvel L, Kleta R, Gahl WA: Genetic basis of cystinosis in Turkish patients: a single-center experience. Pediatr Nephrol 2012;27:115-121.

21 Bertholet-Thomas A, Bacchetta J, Tasic V, Cochat P: Nephropathic cystinosis-a gap between developing and developed nations. $\mathrm{N}$ Engl J Med 2014;370:1366-1367.

22 Alcantara-Ortigoza MA, Belmont-Martinez L, Vela-Amieva M, Gonzalez-Del Angel A: Analysis of the CTNS gene in nephropathic cystinosis Mexican patients: report of four novel mutations and identification of a false positive 57-kb deletion genotype with LDM2/exon 4 multiplex PCR assay. Genet Test 2008; 12:409-414

23 Owen EP, Nandhlal J, Leisegang F, Van der Watt G, Nourse P, Gajjar P: Common mutation causes cystinosis in the majority of black South African patients. Pediatr Nephrol 2015; 30:595-601.

24 Soliman NA, El-Baroudy R, Rizk A, Bazaraa $\mathrm{H}$, Younan A: Nephropathic cystinosis in children: an overlooked disease. Saudi J Kidney Dis Transpl 2009;20:436-442.

25 Freed KA, Blangero J, Howard T, Johnson MP, Curran JE, Garcia YR, Lan HC, Abboud HE, Moses EK: The $57 \mathrm{~kb}$ deletion in cystinosis patients extends into TRPV1 causing dysregulation of transcription in peripheral blood mononuclear cells. J Med Genet 2011; 48:563-566.

26 Rupar CA, Matsell D, Surry S, Siu V: A G339R mutation in the CTNS gene is a common cause of nephropathic cystinosis in the south western Ontario Amish Mennonite population. J Med Genet 2001;38:615-616.

27 Cherqui S, Kalatzis V, Trugnan G, Antignac C: The targeting of cystinosin to the lysosomal membrane requires a tyrosine-based signal and a novel sorting motif. J Biol Chem 2001; 276:13314-13321.

28 Taranta A, Petrini S, Palma A, Mannucci L, Wilmer MJ, De Luca V, Diomedi-Camassei F, Corallini S, Bellomo F, van den Heuvel LP, Levtchenko EN, Emma F: Identification and subcellular localization of a new cystinosin isoform. Am J Physiol Renal Physiol 2008; 294:F1101-F1108.

29 Bellomo F, Taranta A, Petrini S, Venditti R, Rocchetti MT, Rega LR, Corallini S, Gesualdo L, De Matteis MA, Emma F: Carboxyl-terminal sslkg motif of the human cystinosin-lkg plays an important role in plasma membrane sorting. PLoS One 2016;11:e0154805.

30 Kalatzis V, Nevo N, Cherqui S, Gasnier B, Antignac C: Molecular pathogenesis of cystinosis: effect of CTNS mutations on the transport activity and subcellular localization of cystinosin. Hum Mol Genet 2004;13:1361-1371.

31 Settembre C, Fraldi A, Medina DL, Ballabio A: Signals from the lysosome: a control centre for cellular clearance and energy metabolism. Nat Rev Mol Cell Biol 2013;14:283-296.

32 Zoncu R, Bar-Peled L, Efeyan A, Wang S, Sancak Y, Sabatini DM: mTORC1 senses lysosomal amino acids through an inside-out mechanism that requires the vacuolar $\mathrm{H}(+)$ ATPase. Science 2011;334:678-683.

33 Andrzejewska Z, Nevo N, Thomas L, Chhuon C, Bailleux A, Chauvet V, Courtoy PJ, Chol M, Guerrera IC, Antignac C: Cystinosin is a component of the vacuolar $\mathrm{H}+$-ATPase-ragulator-rag complex controlling mammalian target of rapamycin complex 1 signaling. J Am Soc Nephrol 2016;27:1678-1688.

34 Ivanova EA, van den Heuvel LP, Elmonem MA, De Smedt H, Missiaen L, Pastore A, Mekahli D, Bultynck G, Levtchenko EN: Altered mTOR signalling in nephropathic cystinosis. J Inherit Metab Dis 2016;39:457-464.

35 Rega LR, Polishchuk E, Montefusco S, Napolitano G, Tozzi G, Zhang J, Bellomo F, Taranta A, Pastore A, Polishchuk R, Piemonte F, Medina DL, Catz SD, Ballabio A, Emma F: Activation of the transcription factor $\mathrm{EB}$ rescues lysosomal abnormalities in cystinotic kidney cells. Kidney Int 2016;89:862-873.

36 Zhang J, Johnson JL, He J, Napolitano G, Ramadass M, Rocca C, Kiosses WB, Bucci C, Xin Q, Gavathiotis E, Cuervo AM, Cherqui S, Catz SD: Cystinosin, the small GTPase Rab11, and the Rab7 effector RILP regulate intracellular trafficking of the chaperone-mediated autophagy receptor LAMP2A. J Biol Chem 2017;292:10328-10346.

37 Napolitano G, Johnson JL, He J, Rocca CJ, Monfregola J, Pestonjamasp K, Cherqui S, Catz SD: Impairment of chaperone-mediated autophagy leads to selective lysosomal degradation defects in the lysosomal storage disease cystinosis. EMBO Mol Med 2015;7:158-174.
38 Ruivo R, Bellenchi GC, Chen X, Zifarelli G, Sagne C, Debacker C, Pusch M, Supplisson S, Gasnier B: Mechanism of proton/substrate coupling in the heptahelical lysosomal transporter cystinosin. Proc Natl Acad Sci U S A 2012;109:E210-E217.

39 Nevo N, Thomas L, Chhuon C, Andrzejewska Z, Lipecka J, Guillonneau F, Bailleux A, Edelman A, Antignac C, Guerrera IC: Impact of cystinosin glycosylation on protein stability by differential dynamic stable isotope labeling by amino acids in cell culture (SILAC). Mol Cell Proteomics 2017;16:457-468.

40 Cherqui S, Sevin C, Hamard G, Kalatzis V, Sich M, Pequignot MO, Gogat K, Abitbol M, Broyer M, Gubler MC, Antignac C: Intralysosomal cystine accumulation in mice lacking cystinosin, the protein defective in cystinosis. Mol Cell Biol 2002;22:7622-7632.

41 Nevo N, Chol M, Bailleux A, Kalatzis V, Morisset L, Devuyst O, Gubler MC, Antignac C: Renal phenotype of the cystinosis mouse model is dependent upon genetic background. Nephrol Dial Transplant 2010;25:1059-1066.

42 Emma F, Nesterova G, Langman C, Labbe A, Cherqui S, Goodyer P, Janssen MC, Greco M, Topaloglu R, Elenberg E, Dohil R, Trauner D, Antignac C, Cochat P, Kaskel F, Servais A, Wuhl E, Niaudet P, Van't Hoff W, Gahl W, Levtchenko E: Nephropathic cystinosis: an international consensus document. Nephrol Dial Transplant 2014;29(suppl 4):iv87-iv94.

43 Festa BP, Chen Z, Berquez M, Debaix H, Tokonami N, Prange JA, Hoek GV, Alessio C, Raimondi A, Nevo N, Giles RH, Devuyst O, Luciani A: Impaired autophagy bridges lysosomal storage disease and epithelial dysfunction in the kidney. Nat Commun 2018;9:161.

44 Gao XD, Wang J, Keppler-Ross S, Dean N: ERS1 encodes a functional homologue of the human lysosomal cystine transporter. FEBS J 2005;272:2497-2511.

45 Gao M, Kaiser CA: A conserved GTPase-containing complex is required for intracellular sorting of the general amino-acid permease in yeast. Nat Cell Biol 2006;8:657-667.

46 Simpkins JA, Rickel KE, Madeo M, Ahlers BA, Carlisle GB, Nelson HJ, Cardillo AL, Weber EA, Vitiello PF, Pearce DA, Vitiello SP: Disruption of a cystine transporter downregulates expression of genes involved in sulfur regulation and cellular respiration. Biol Open 2016;5:689-697.

47 Deshpande AA, Shukla A, Bachhawat AK: A Genetic screen for investigating the human lysosomal cystine transporter, cystinosin. Sci Rep 2018;8:3442.

48 Elmonem MA, Khalil R, Khodaparast L, Khodaparast L, Arcolino FO, Morgan J, Pastore A, Tylzanowski P, Ny A, Lowe M, de Witte PA, Baelde HJ, van den Heuvel LP, Levtchenko E: Cystinosis (CTNS) zebrafish mutant shows pronephric glomerular and tubular dysfunction. Sci Rep 2017;7:42583.

49 Cherqui S: Cysteamine therapy: a treatment for cystinosis, not a cure. Kidney Int 2012;81: 127-129.
Geographic Distribution and Functional

Consequences of Mutations in CTNS Gene
Nephron 2019;141:133-146 DOI: $10.1159 / 000495270$ 
50 Syres K, Harrison F, Tadlock M, Jester JV, Simpson J, Roy S, Salomon DR, Cherqui S: Successful treatment of the murine model of cystinosis using bone marrow cell transplantation. Blood 2009;114:2542-2552.

51 Beck M: Treatment strategies for lysosomal storage disorders. Dev Med Child Neurol 2018;60:13-18.

52 Yeagy BA, Harrison F, Gubler MC, Koziol JA, Salomon DR, Cherqui S: Kidney preservation by bone marrow cell transplantation in hereditary nephropathy. Kidney Int 2011;79:11981206.

53 Elmonem MA, Veys K, Oliveira Arcolino F, Van Dyck M, Benedetti MC, Diomedi-Camassei F, De Hertogh G, van den Heuvel LP, Renard M, Levtchenko E: Allogeneic HSCT transfers wild-type cystinosin to nonhematological epithelial cells in cystinosis: first human report. Am J Transplant 2018;18:2823-2828.
54 Harrison F, Yeagy BA, Rocca CJ, Kohn DB, Salomon DR, Cherqui S: Hematopoietic stem cell gene therapy for the multisystemic lysosomal storage disorder cystinosis. Mol Ther 2013;21:433-444.

55 Naphade S, Sharma J, Gaide Chevronnay HP, Shook MA, Yeagy BA, Rocca CJ, Ur SN, Lau AJ, Courtoy PJ, Cherqui S: Brief reports: lysosomal cross-correction by hematopoietic stem cell-derived macrophages via tunneling nanotubes. Stem Cells 2015;33:301-309.

56 Corallini S, Taranta A, Bellomo F, Palma A, Pastore A, Emma F: Transcriptional and posttranscriptional regulation of the CTNS gene. Pediatr Res 2011;70:130-135.

57 Bellomo F, Corallini S, Pastore A, Palma A, Laurenzi C, Emma F, Taranta A: Modulation of CTNS gene expression by intracellular thiols. Free Radic Biol Med 2010;48: 865-872.
58 Biffi A, Montini E, Lorioli L, Cesani M, Fumagalli F, Plati T, Baldoli C, Martino S, Calabria A, Canale S, Benedicenti F, Vallanti G, Biasco L, Leo S, Kabbara N, Zanetti G, Rizzo WB, Mehta NA, Cicalese MP, Casiraghi M, Boelens JJ, Del Carro U, Dow DJ, Schmidt M, Assanelli A, Neduva V, Di Serio C, Stupka E, Gardner J, von Kalle C, Bordignon C, Ciceri F, Rovelli A, Roncarolo MG, Aiuti A, Sessa M, Naldini L: Lentiviral hematopoietic stem cell gene therapy benefits metachromatic leukodystrophy. Science 2013; 341:1233158.

59 Arcolino FO, Zia S, Held K, Papadimitriou E, Theunis K, Bussolati B, Raaijmakers A, Allegaert K, Voet T, Deprest J, Vriens J, Toelen J, van den Heuvel L, Levtchenko E: Urine of preterm neonates as a novel source of kidney progenitor cells. J Am Soc Nephrol 2016;27: 2762-2770. 